\title{
Analysis on Spatio-Temporal Dynamic Evolution of Relative Resource Carrying Capacity of Coal Cities Based on PLE-EM-CPM Model
}

\author{
Gang He ${ }^{1,2}$, Shuhang Zhao ${ }^{1 *}$, Keyu Bao ${ }^{1}$, Jie Li ${ }^{1}$ \\ ${ }^{1}$ School of Economy and Management, Anhui University of Science and Technology, Huainan, Anhui, 232001, China \\ ${ }^{2}$ State Key Laboratory of Mining Response and Disaster Prevention and Control in Deep Coal Mines, \\ Huainan, Anhui, 232001, China
}

Received: 13 June 2021

Accepted: 24 October 2021

\begin{abstract}
Coal cities are the impetus and guarantee of China's economic development. However, the longterm unreasonable exploitation of coal seriously affects the quality of eco-environment and residents' lives in coal cities. This study takes five coal cities in Anhui Province as the research objects, selects ten evaluation indicators of three dimensions based on the production-life-ecology (PLE) model, and improves the evaluation model of relative resource carrying capacity (RRCC). The relative carrying capacity (RCC) of various resources and the relative resource comprehensive carrying capacity (RRCCC) in coal cities from 2010 to 2019 are calculated by entropy-catastrophe progression method to explore the spatio-temporal dynamic evolution of RRCCC in each city, and the critical resistance factors are identified by resistance model. The results show that: (1) There is a particular gap between the RCC of various resources and the existing population resources. (2) RRCCC, with a good development trend in general, is at a relatively strong load level, tending to a strong load level. (3) The level of RRCCC in each city is unevenly distributed, with regional differences. (4) The ecological subsystem had the most significant impact on RRCCC before, and it will be replaced by the production subsystem in the future.
\end{abstract}

Keywords: coal cities, catastrophe progression method, entropy method, resistance model, relative resource carrying capacity

\section{Introduction}

Coal resources, which account for more than $70 \%$ of the total fossil energy, are the core impetus of China's economic production and the energy guarantee of social life. Therefore, many coal cities have formed

e-mail: ZSHang1001@163.com centered on coal regions, typical resource-based cities, accounting for more than $60 \%$. However, excessive exploitation in coal cities will inevitably lead to contradictions such as insufficient total resources, eco-environmental damage, and industrial decline [1]. The fundamental reason that hinders the rapid development of coal cities is that excessive human activities exceed the carrying capacity of resources and the environment [2]. 
Long-term unreasonable coal exploitation can cause air pollution [3-5], and air quality is a basic condition for human sustainable development. $\mathrm{CO}_{2}$ and particulate matter produced by coal exploitation are the main factors affecting air quality. At the same time, the industrial waste water produced contains a lot of heavy metals, which are difficult to dissolve and easy to accumulate in organisms, resulting in water pollution [6-7]. In addition, coal exploitation will also cause geological disasters such as land destruction [8], vegetation degradation [9], mining area collapse [10] and gas explosion [11]. Building green mines in the new era has become the primary task of relevant departments. To speed up the clean and efficient pace of coal city resources exploitation and achieve the high quality and sustainable development of coal city, it is necessary to promote the ecological safety construction of coal city. Therefore, how to measure the carrying capacity of coal city resources and determine its critical influencing factors is particularly important.

The application of carrying capacity in ecology and demography is pervasive [12-13]. Its origin can trace back to Malthus's An essay on the principle of population [14] published in 1798. The earliest mathematical expression of carrying capacity was proposed by Verhulst (1838) based on the theory in Malthus's book [15]. Park and Burgoss (1921) put forward the concept of carrying capacity and defined it as "the maximum limit that can accommodate individual organisms under specific environmental conditions" [16]. The evolution and development of carrying capacity generally experienced four stages: population carrying capacity, resource carrying capacity, environmental carrying capacity, and ecological carrying capacity [17-21].

Population growth has always been the main source of socio-economic problems [22]. With the advance of green urbanization, the population in the urban center is more concentrated, and the resource carrying capacity (RCC) can be used to measure the capacity of the population in the study area [21]. With the continuous indepth exploration of research fields, the research objects of resource carrying capacity have been extended from natural resources such as water resources and land resources [23-25] in the early stage to tourism resources [26], social resources [27], ecological resources [28-29] and environmental resources [30]. The main research methods include system dynamics [25, 31], TOPSIS [30], ecological footprint [32] and AHP [28, 31, 33], etc. Domestic and foreign scholars have evaluated the level of various resource carrying capacity from multidimensional and multi-perspective.

Due to the large but unevenly distributed total of population and resources in China and the differences in resource endowment, the traditional evaluation methods only study a single region or resource,which cannot directly reflect the differences in carrying capacity among various study areas and resources, as well as the complementarity of superior and inferior resources [28-33]. To solve the influence of this problem on the study, Huang (2000) put forward the concept of relative resource carrying capacity (RRCC), that is, an area larger than the study area is selected as the reference area, and the relative carrying capacity (RCC) of various resources in the study area are calculated by the formula of resource stock or total consumption in the reference area and the study area [34]. Therefore, compared with the single RCC, RRCC is more meaningful for evaluating the carrying capacity level of coal cities.

RRCC has been applied to the study of regional resource carrying capacity by the majority of scholars. Yang, Bao and Zeng modified the RRCC model to study the temporal and spatial dynamic evolution of Jiangsu, Anhui and Hunan provinces [35-37]. Zeng and $\mathrm{Su}$ used the RRCC theory to evaluate and predict the relative water resources carrying capacity of Hunan and Gansu provinces [37-38]. With the help of the RRCC model, Peng selected two reference areas to measure the longitudinal time change of RRCC in Guiyang City [39]. Li and Wang evaluated the sustainable development of industries in ethnic minority areas and ecologically fragile sites from the perspective of RRCC [40-41]. It can be seen that few scholars choose coal cities as research objects.

Through the study of domestic and foreign literature [35-41], it can be concluded that scholars in the academic circle are relatively approved of the RRCC evaluation model. However, the model still needs to be improved and perfected. First, in the dimension of subsystem selection, it can be summarized into four dimensions: natural resources, social resources, economic resources, and ecological resources. The selection dimension is relatively single, and the research perspective is not innovative enough. Second, in determining the weight of indicators, AHP is the primary method, which is too subjective and has subjective errors. Third, in selecting research methods, it is difficult to combine or compare multiple methods, and their advantages cannot be complementary, resulting in a low matching degree of the RRCC evaluation model.

Based on the relevant research basis, combined with the concept of "integration of production, life, and ecology", the coal city is linked to production, life, and ecology, and ten representative evaluation indicators are selected to construct a new research perspective in line with the ecological safety construction of mining areas. According to the standard of coal cities, five coal cities in Anhui Province are selected as the research objects $[1,36,42]$. The entropy method is used to determine the weight to avoid subjective weighting error. The RRCC evaluation model is improved by using the catastrophe progression method and carrying capacity resistance to evaluate the RRCC and identify the critical resistance factors. The ArcGIS10.7 software is used to analyze the spatial and temporal dynamic evolution of the study area from 2010 to 2019, and the internal factors of its change were studied. This study optimizes and improves the RRCC evaluation model to provide a theoretical basis 
and decision-making basis for realizing the ecological safety construction of coal cities.

\section{Materials and Methods}

\section{Study Area}

The study area is located in the northern part of Anhui Province, China, between latitude $31^{\circ} 54^{\prime}-34^{\circ} 39^{\prime} \mathrm{N}$ and longitude $114^{\circ} 52^{\prime}-118^{\circ} 11^{\prime} \mathrm{E}$, with a total area of $9,379 \mathrm{~km}^{2}$. The coal resources reserves in the study area rank among the top ten in China [36]. The study area is the core energy base of the Huaihe River ecological economic belt [43]. The Yangtze River flows through the province where water transportation is convenient. In 2019, Anhui's total energy production amounted to 89.44 million tons of standard coal, including 109.90 million tons of raw coal, with a GDP of 3.71 trillion yuan.The population density was 2,663.61 people per square kilometer, which is nearly six times that of Anhui Province. The vast population size affects the high-quality and sustainable development of coal cities. Anhui Province has sixteen cities as the reference area. Five coal cities, including Huainan, Suzhou, Huaibei, Bozhou and Fuyang, are selected as the study area, as shown in Fig. 1.

\section{The Evaluation System}

This paper integrates the concept of production-lifeecology (PLE) [44], transforms the traditional natural resources, social resources and economic resources subsystems into production resources and life resources subsystems, as well as retains the original ecological resources subsystem. The idea comes from China's strategy for rural revitalization, and coal cities also need revitalization and transformation development. Considering the influence of various resources on the RRCC evaluation model and combining the characteristics of the study area, ten evaluation indicators (Table 1) are selected to construct the comprehensive evaluation system of RRCC [29, 33-36, 39].

\section{Productive Resources Subsystem}

In this paper, water resources, agricultural land resources, scientific and technological resources and industrial enterprise resources are taken as four elements of the production resources subsystem. Water and soil resources are the basic guarantee of human activities, so the total water resources are selected as the measurement standard of water resources. As the administrative area of the city basically does not change

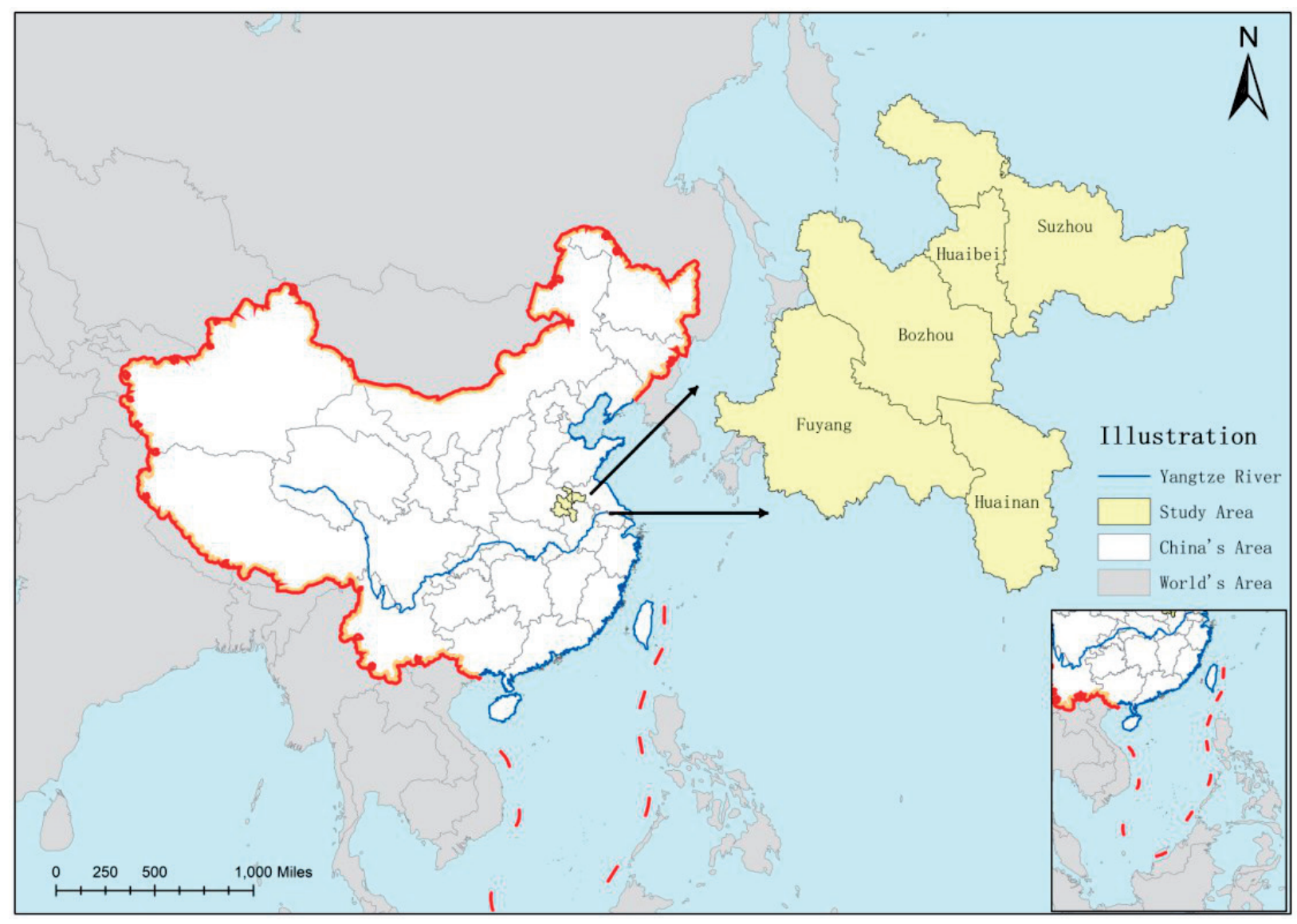

Fig. 1. Map showing the location of the study area in China. 
Table 1. The RRCC comprehensive evaluation indicator system of coal cities.

\begin{tabular}{|c|c|c|c|}
\hline Target layer & Element layer & Sub-element layer & Indicator layer \\
\hline \multirow{10}{*}{$\begin{array}{c}\text { The RRCC } \\
\text { of coal } \\
\text { cities }\end{array}$} & \multirow{4}{*}{$\begin{array}{l}\text { Production } \\
\text { resources }\end{array}$} & $\mathrm{C}_{1}$-Water resources & Total water resources \\
\hline & & $\mathrm{C}_{2}$-Agricultural land resources & Effective irrigated area \\
\hline & & $\mathrm{C}_{3}$-Scientific and technological resources & R\&D development expenditure \\
\hline & & $\mathrm{C}_{4}$-Industrial enterprise resources & Number of industrial enterprises above designated size \\
\hline & \multirow{3}{*}{ Life resources } & $\mathrm{C}_{5}$-Economic resources & GDP \\
\hline & & $\mathrm{C}_{6}$-Education resources & $\begin{array}{l}\text { Number of students in ordinary colleges and } \\
\text { universities }\end{array}$ \\
\hline & & $\mathrm{C}_{7}$-Medical resources & Number of staff in medical and health institutions \\
\hline & \multirow{3}{*}{$\begin{array}{l}\text { Ecological } \\
\text { resources }\end{array}$} & $\mathrm{C}_{8}$-Forestry resources & Afforestation area \\
\hline & & $\mathrm{C}_{9}$-Ecological compensation resources & Ecological environment water replenishment \\
\hline & & $\mathrm{C}_{10}$-Disaster prevention resources & Investment in geological disaster prevention\&control \\
\hline
\end{tabular}

much, the effective irrigated area is selected as the measurement indicator of land resources to evaluate the level of agricultural production. It is relatively common for scholars to study energy resources in coal cities, and the accuracy of energy resources data acquisition is low. Therefore, two major resources, science\&technology and industrial enterprise, are selected in this paper for comprehensive investigation. Taking R\&D development expenditure and the number of industrial enterprises above designated size as measurement indicators, the influence of scientific and technological input and enterprise size on energy production are studied.

\section{Life Resources Subsystem}

The subsystem of life resources includes three parts: economic resources, educational resources and medical resources. In the past, the research objects were usually social resources and economic resources. Combining the concept of "new education and new medical treatment", this paper replaces social resources with educational resources and medical resources. The number of students in ordinary colleges and universities and the number of staff in medical and health institutions are selected as the evaluation indicators, and the GDP is selected as the measurement indicator of economic resources. High-quality socio-economic development in coal cities has improved people's quality of life.

\section{Ecological Resources Subsystem}

The subsystem of ecological resources is constituted from three dimensions: forestry resources, ecological compensation resources and disaster prevention resources. Scholars mostly choose the total capital investment in urban greening and environmental protection as the research focus. However, from the perspective of ecological compensation, this paper selects afforestation area, ecological environment water replenishment, and investment in geological disaster prevention\&control as the measurement indicators to comprehensively investigate the ecological resources level of coal cities.

\section{Data Source}

The research data in this paper come from the Statistical Yearbook of Anhui Province of China(2011-2020), the Statistical Yearbook of each city (2011-2020) and the relevant data provided by the Statistics Bureau of Anhui Province and five cities. Some data are calculated according to the Yearbook data.

\section{Evaluation Model}

Based on PLE model, RRCC model is improved to calculate the RRCC of coal cities. The weight of indicators are calculated and sorted by entropy method $[23,45]$. Then, combined with the catastrophe progression method [46-48], the index and grade of each subsystem and RRCCC are obtained, and the spatiotemporal dynamic evolution analysis is conducted. Finally, the resistance model is used to identify the critical resistance factors.

\section{PLE Model}

The RRCC of 10 resource indicators in three subsystems of Production resources-Life resourcesEcological resources (PLE) are calculated:

$$
C_{k}=\frac{P}{Q_{k}} \times Q_{k}{ }^{\prime}
$$

Among them, $C_{k}$ represents the population accommodated by a certain resource, $P$ is the total 
population of the reference area, $Q_{k}$ is the total resource in the reference area, and $Q_{k}{ }^{\prime}$ is the total resource in the study area.

\section{EM-CPM Model}

EM-CPM model is composed of entropy method and catastrophe progression method to evaluate the relative resource carrying capacity. Catastrophe progression method is proposed based on catastrophe theory [48]. CPM first divides the evaluation elements according to the level, and selects the corresponding potential function according to the number of control variables. Because the units of control variables are not unified, the normalization formula should be derived through the bifurcation set to solve the problem. Finally, the total membership grade is calculated, then the ranking analysis is carried out according to the size. The common types of catastrophe are shown in Table 2.

(1) Data Standardization:

Positive indicator:

$x_{i j}=\frac{a_{i j}-\min \left\{a_{i j}\right\}}{\max \left\{a_{i j}\right\}-\min \left\{a_{i j}\right\}} \quad(i=1,2, \ldots, m, j=1,2, \ldots, n)$

Reverse indicator:

$x_{i j}=\frac{\max \left\{a_{i j}\right\}-a_{i j}}{\max \left\{a_{i j}\right\}-\min \left\{a_{i j}\right\}} \quad(i=1,2, \ldots, m, j=1,2, \ldots, n)$
(2) Calculating entropy:

$$
e_{j}=-\frac{1}{\ln m} \sum_{i=1}^{m}\left(\frac{x_{i j}}{\sum_{i=1}^{m} x_{i j}} \ln \frac{x_{i j}}{\sum_{i=1}^{m} x_{i j}}\right), e_{j} \in[0,1]
$$

(3) Calculating weight:

$$
w_{j}=\frac{1-e_{j}}{\sum_{j=1}^{n}\left(1-e_{j}\right)}
$$

(4) The catastrophe type and the corresponding potential function are determined according to the number of indicators at each level. The indicators at each level are sorted from large to small, so as to eliminate the subjective error of artificial sorting.

(5) The standardized data are substituted into the normalization formula to calculate the catastrophe progression of each control variable. Then the catastrophe progression of the subsystem is taken as the control variable of each indicator of the upper evaluation system. Because of the complementarity among the resource indicators in the evaluation system, it belongs to the complementary catastrophe model, the mean value method is selected.

\begin{tabular}{|c|c|c|c|c|}
\hline $\begin{array}{l}\text { Type of catastrophe } \\
\text { model }\end{array}$ & $\begin{array}{l}\text { Number of control } \\
\text { variables }\end{array}$ & Potential function & Bifurcation set & $\begin{array}{l}\text { Normalization } \\
\text { formula }\end{array}$ \\
\hline Folding model & 1 & $f(x)=x^{3}+a x$ & $a=-3 x^{2}$ & $x_{a}=a^{\frac{1}{2}}$ \\
\hline Cusp model & 2 & $f(x)=x^{4}+a x^{2}+b x$ & $\begin{array}{c}a=-6 x^{2} \\
b=8 x^{3}\end{array}$ & $\begin{array}{l}x_{a}=a^{\frac{1}{2}} \\
x_{b}=b^{\frac{1}{3}}\end{array}$ \\
\hline Swallowtail model & 3 & $f(x)=\frac{1}{5} x^{5}+\frac{1}{3} a x^{3}+\frac{1}{2} b x^{2}+c x$ & $\begin{array}{c}a=-6 x^{2} \\
b=8 x^{3} \\
c=-3 x^{4}\end{array}$ & $\begin{array}{l}x_{a}=a^{\frac{1}{2}} \\
x_{b}=b^{\frac{1}{3}} \\
x_{c}=c^{\frac{1}{4}}\end{array}$ \\
\hline Butterfly model & 4 & $f(x)=\frac{1}{6} x^{6}+\frac{1}{4} a x^{4}+\frac{1}{3} b x^{3}+\frac{1}{2} c x^{2}+d x$ & $\begin{array}{c}a=-10 x^{2} \\
b=20 x^{3} \\
c=-15 x^{4} \\
d=4 x^{5}\end{array}$ & $\begin{array}{l}x_{a}=a^{\frac{1}{2}} \\
x_{b}=b^{\frac{1}{3}} \\
x_{c}=c^{\frac{1}{4}} \\
x_{d}=d^{\frac{1}{5}}\end{array}$ \\
\hline
\end{tabular}

Table 2. The four types of catastrophe models. 
Table 3. The RRCC index and grade criteria.

\begin{tabular}{|c|c|c|c|c|c|}
\hline Grade & Control variables & Ecology/Life RCCC index & Production RCCC index & RRCC index & RRCC grade \\
\hline I & {$[0,0.2)$} & {$[0,0.567)$} & {$[0,0.606)$} & {$[0,0.822)$} & Low load \\
\hline II & {$[0.2,0.4)$} & {$[0.567,0.722)$} & {$[0.606,0.749)$} & {$[0.822,0.893)$} & Relatively low load \\
\hline III & {$[0.4,0.6)$} & {$[0.722,0.833)$} & {$[0.749,0.850)$} & {$[0.893,0.938)$} & Medium load \\
\hline IV & {$[0.6,0.8)$} & {$[0.833,0.923)$} & {$[0.850,0.931)$} & {$[0.938,0.972)$} & Relatively strong load \\
\hline V & {$[0.8,1.0]$} & {$[0.923,1.000]$} & {$[0.931,1.000]$} & {$[0.972,1.000]$} & Strong load \\
\hline
\end{tabular}

(6) Establishing evaluation grade standard. Because the difference of membership grade calculated by EM-CPM is usually relatively small, it is difficult to compare. In order to make the study more valuable, this paper establishes the evaluation grade standard [47], selects the control variable $\{0.2,0.4,0.6,0.8,1\}$, calculates the membership grade of each level step by step, and finally obtains the total membership grade, so as to determine the value interval of each evaluation grade (Table 3).

\section{Resistance Model}

To accelerate the development and transformation of coal cities, it is of great significance to identify the pros and cons of the influencing factors. With the help of the resistance model [49], the critical resistance factors affecting the RRCC of coal cities are diagnosed. The formula is as follows:

$$
O=\frac{s_{i j} w_{j}}{\sum_{j=1}^{n}\left(s_{i j} w_{j}\right)}
$$

Among them, the resistance value $O$ represents the resistance degree of the factor; The skewness is
$S_{i j}=1-x_{i j}$, which represents the difference between the factor and optimal value.

\section{Results}

Time Series Change of RCC of Various Resources

During the study period, the population of coal cities increased steadily from 22.29 million in 2010 to 24.98 million in 2019 , an increase of $12.1 \%$. Taking Anhui Province as the reference area, formula (1) is used to calculate the RCC of various resources in coal cities from 2010 to 2019, as shown in Table 4.

In terms of the mean value of the RRCC, the total population was 23.54 million, which exceeds the mean values of various resources' RCC. Moreover, the RCC of various resources was greatly different, and the ranking was based on the mean value: agricultural land resources $>$ medical resources $>$ industrial enterprise resources $>$ economic resources $>$ forestry resources $>$ ecological compensation resources $>$ education resources $>$ water resources $>$ scientific and technological resources $>$ disaster prevention resources.

Among them, agricultural land resources were the closest to the total population, exceeding the RCC

Table 4. The RCC of various resources in coal cities from 2010 to 2019.

\begin{tabular}{|c|c|c|c|c|c|c|c|c|c|c|c|}
\hline Year & $\mathrm{C}_{1}$ & $\mathrm{C}_{2}$ & $\mathrm{C}_{3}$ & $\mathrm{C}_{4}$ & $\mathrm{C}_{5}$ & $\mathrm{C}_{6}$ & $\mathrm{C}_{7}$ & $\mathrm{C}_{8}$ & $\mathrm{C}_{9}$ & $\mathrm{C}_{10}$ & $\begin{array}{c}\text { Total } \\
\text { population }\end{array}$ \\
\hline 2010 & 5.83 & 21.90 & 5.94 & 11.81 & 14.22 & 10.04 & 18.11 & 13.59 & 11.00 & 1.32 & 22.29 \\
\hline 2011 & 7.72 & 22.20 & 6.05 & 13.54 & 13.83 & 10.04 & 20.62 & 10.44 & 5.58 & 0.25 & 22.31 \\
\hline 2012 & 6.88 & 22.53 & 6.38 & 13.97 & 13.90 & 9.83 & 20.87 & 10.60 & 6.34 & 0.32 & 22.37 \\
\hline 2013 & 8.19 & 21.23 & 6.17 & 15.08 & 13.91 & 9.59 & 21.05 & 8.90 & 6.55 & 0.50 & 22.60 \\
\hline 2014 & 8.01 & 21.51 & 5.95 & 15.57 & 13.89 & 9.39 & 21.24 & 14.74 & 6.41 & 0.38 & 22.84 \\
\hline 2015 & 6.11 & 24.19 & 5.72 & 16.44 & 14.26 & 9.47 & 21.46 & 14.97 & 6.52 & 2.20 & 24.10 \\
\hline 2016 & 6.05 & 24.46 & 5.60 & 16.79 & 14.29 & 9.54 & 22.22 & 15.35 & 12.86 & 0.39 & 24.36 \\
\hline 2017 & 10.94 & 24.94 & 5.75 & 17.36 & 14.29 & 9.59 & 22.29 & 12.23 & 19.36 & 1.38 & 24.63 \\
\hline 2018 & 11.41 & 25.34 & 6.23 & 17.47 & 14.30 & 9.63 & 22.70 & 9.94 & 18.87 & 1.10 & 24.87 \\
\hline 2019 & 7.33 & 25.68 & 6.17 & 16.55 & 15.11 & 10.26 & 22.33 & 11.23 & 17.87 & 7.50 & 24.98 \\
\hline Mean & 7.84 & 23.40 & 6.00 & 15.46 & 14.20 & 9.74 & 21.29 & 12.20 & 11.14 & 1.53 & 23.54 \\
\hline
\end{tabular}


of other kinds of resources. Its RCC was 23.40 million, which was only 0.14 million less than the total population of coal cities. Moreover, Anhui Province is a traditional agricultural province, so agricultural land resources are crucial for promoting the development of coal cities in Anhui Province. Compared with Anhui Province, its coal cities also had relatively adequate medical resources, with the RCC of 21.29 million, laying a critical foundation for steady population growth. However, the RCC of other kinds of resources were far lower than the total population. According to the data, the total population of coal cities put the greatest pressure on disaster prevention resources, as well as scientific and technological resources and water resources were also at a relatively scarce level.

From the time series change trend of various resources, it can be seen from Fig. 2 that the RCC of agricultural land resources showed a steady growth trend with a small increase, but it exceeded the actual population resources from 2015 to 2019. It indicates that the agricultural land management of coal cities strived for steady progress, and agriculture is an indispensable part of the development of coal cities. The RCC of medical resources and industrial enterprise resources had a relatively large increase in 2011, and then showed a steady upward trend with a small increase and declined slightly in 2019. The change trend of the two kinds of resources were consistent, indicating that medical resources was protecting the healthy development of industrial enterprises while protecting the population resources. The RCC of economic resources, educational resources and scientific and technological resources remained basically stable, and the development of social economy, science and education in coal cities were relatively stable.
The RCC of forestry resources showed a fluctuating downward trend: the fluctuation decreased from 2010 to 2013, reaching the lowest level of 8.90 million in 2013. After a sharp increase from 2014 to 2016, it remained stable, but then showed a downward trend and rebounded slightly in 2019. While ensuring steady economic development in coal cities, there is a lack of protection of forest resources, as well as the supervision of forestry departments is inadequate. The RCC of ecological compensation resources varied greatly, with the fluctuation interval ranging from 6.34 million to 19.36 million, which was closely related to the ecological protection and the investment of environmental governance in coal cities. The RCC of water resources showed a fluctuating trend, with two rising trends from 2010 to 2016. However, in 2016, it basically remained the same as in 2010. In 2017-2018, it increased significantly and remained stable, however, it tended to be lower in 2019, which was related to the uneven rainfall in coal cities and unreasonable water replenishment of ecological environment. The RCC of disaster prevention resources increased by $467 \%$ during the study period, but there was a very serious gap with the actual population resources, which obviously could not meet the current standard of natural disaster prevention and control for coal cities in Anhui Province.

\section{Change of RRCCC of Coal Cities}

On the basis of standardized data of various resources, EM-CPM model and the four catastrophe models shown in Table 2 can be used to obtain the RRCCC index of coal cities in Anhui Province from 2010 to 2019.

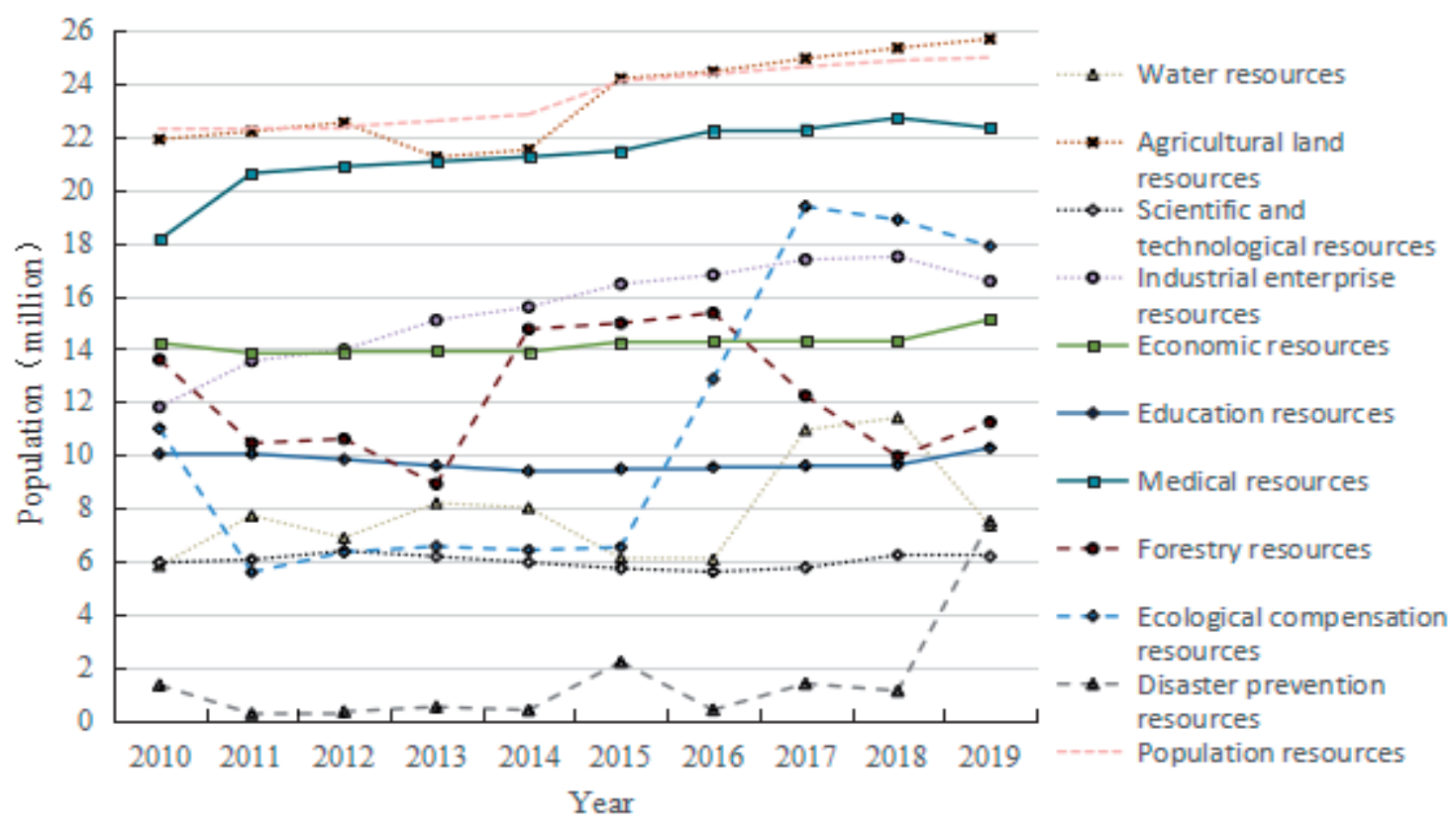

Fig. 2. The time-series change of RCC of various resources in coal cities from 2010 to 2019. 


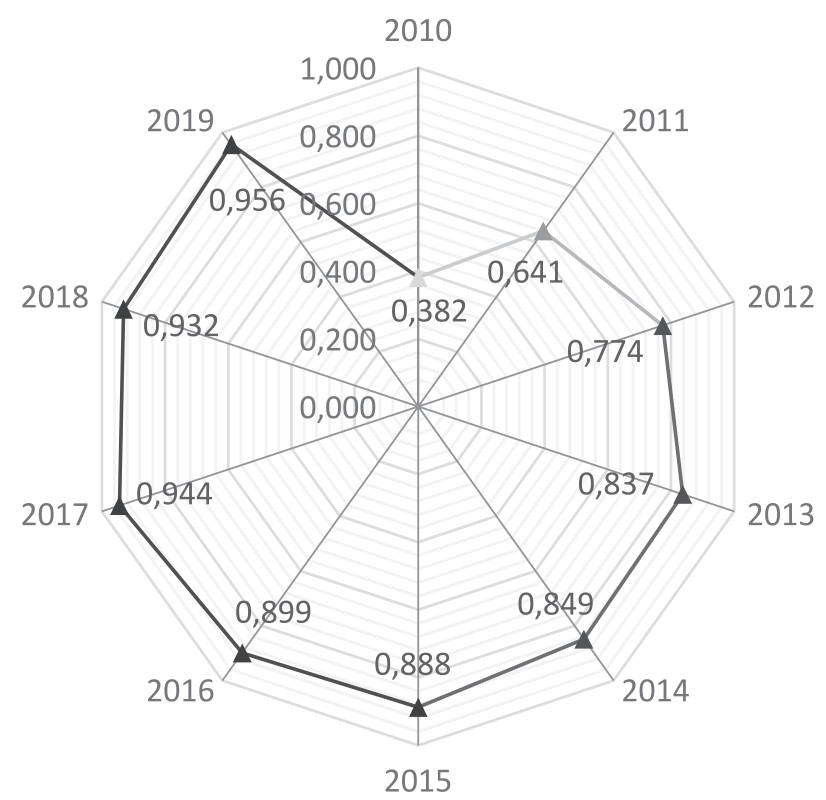

Fig. 3. The changing trend of RRCCC index of coal cities from 2010 to 2019 .

During the study period, the RRCCC index of coal cities showed a steady growth trend, with an overall growth rate as high as $150.26 \%$, as shown in Fig. 3 . The lowest level was 0.382 in 2010 , which increased to 0.641 in 2011 with an increase of $67.80 \%$. It broke through 0.8 in 2013, was between 0.8 and 0.9 from 2013 to 2016, broke through 0.9 in 2017, and reached a peak of 0.956 in 2019. According to the RRCC grade standard shown in Table 3, the evolution process of the RRCCC grade of coal cities was as follows: low loadrelatively low load-medium load- relatively strong load. The overall trend of development is good, with a trend towards strong load. This indicates that the RRCCC is in the rising stage, which is conducive to promoting the high-quality development of coal cities.

\section{Spatio-Temporal Evolution of the RRCCC of Each Coal City}

The RRCCC index and grade of each coal city were calculated by using EM-CPM model and RRCC grade standard in 2010, 2015 and 2019. Combined with Table 5 and Fig. 4, we can see the time series change characteristics and spatial distribution differences of the RRCCC of each coal city.

It can be seen from Table 6 that the uneven grade level distribution of the RRCCC of each city was related to the difference of regional location. Huainan and Huaibei had relatively large index changes, while Bozhou was the only city with relatively large grade changes.

Fuyang was the only city with a higher level of RRCCC, which changed from strong load to relatively strong load and tended to medium load. As a growing resource-based city, Fuyang has sufficient coal reserves, and the production subsystem and life subsystem were at a strong load level, but the ecological subsystem reduced from a relatively strong load level to a relatively low load level, which led to a downward trend in the level of RRCCC.

The cities with relatively low level of RRCCC were Suzhou and Bozhou. The RRCCC of Suzhou had a small change. The index increased as high as 0.242 , but the grade was only upgraded from low load to relatively low load. All subsystems were at a low load level and would remain at a relatively low load level for a long time. Suzhou had many industrial enterprises, but the lack of scientific and technological resources, education resources, disaster prevention resources and ecological compensation resources led to the average level of life resources in all aspects. Bozhou's grade changed greatly, but the index changed little. The grade decreased from relatively strong load to relatively low load, but the index only decreases by 0.093 . Bozhou's ecological subsystem generally maintained at a relatively strong load level, and the life subsystem was originally at a strong load level. But the production subsystem was reduced from a medium load level to a low load level, finally the life subsystem was at a low load level, and the RRCCC dropped to a relatively low load level.

Huainan and Huaibei were the cities with low level of RRCCC. Although Huainan was at a low load level, it reached a relatively low load level in 2015, showing an overall upward trend. In 2010, Huaibei's grade was identified as a relatively low load, but it had been in a low load level since then, showing a downward trend as a whole. Huainan and Huaibei are the two cities with the largest energy output in Anhui Province, but their economic development mainly depends on the coal industry. However, Huainan belongs to the

Table 5. The RRCCC index and grade level in each coal city.

\begin{tabular}{|c|c|c|c|c|c|c|}
\hline City & $\begin{array}{c}2010 \\
\text { RRCC index }\end{array}$ & $\begin{array}{c}2010 \\
\text { RRCC grade }\end{array}$ & $\begin{array}{c}2015 \\
\text { RRCC index }\end{array}$ & $\begin{array}{c}2015 \\
\text { RRCC grade }\end{array}$ & $\begin{array}{c}2019 \\
\text { RRCC index }\end{array}$ & $\begin{array}{c}2019 \\
\text { RRCC grade }\end{array}$ \\
\hline Huainan & 0.477 & Low load & 0.866 & Relatively low load & 0.806 & Low load \\
\hline Suzhou & 0.625 & Low load & 0.876 & Relatively low load & 0.867 & Relatively low load \\
\hline Huaibei & 0.867 & Relatively low load & 0.467 & Low load & 0.568 & Low load \\
\hline Bozhou & 0.941 & Relatively strong load & 0.814 & Low load & 0.848 & Relatively low load \\
\hline Fuyang & 0.978 & Strong load & 0.966 & Relatively strong load & 0.943 & Relatively strong load \\
\hline
\end{tabular}



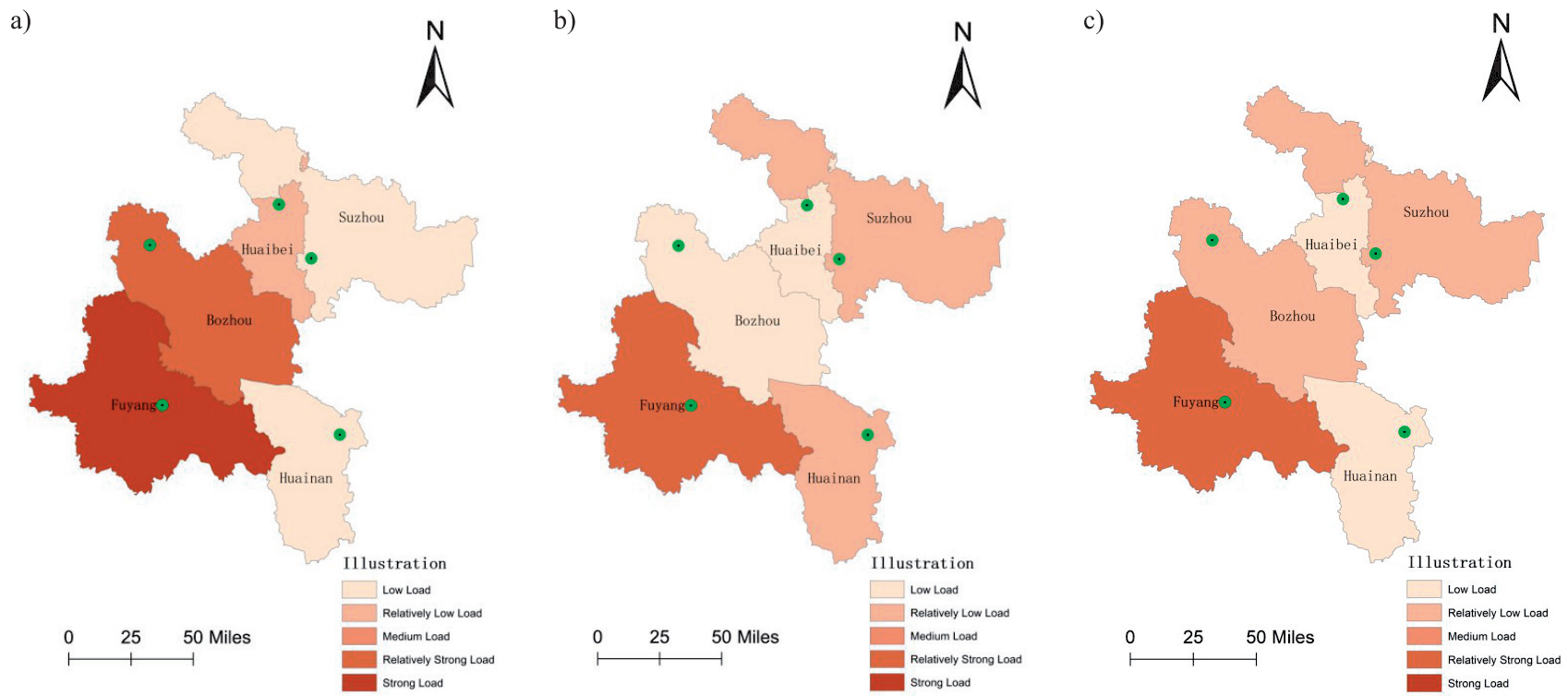

Fig. 4. The spatial distribution differences of RRCCC in each coal city: a) 2010, b) 2015, c) 2019.

Table 6 . The grade changes of the subsystems' RRCC in each coal city.

\begin{tabular}{|c|c|c|c|c|c|c|c|c|c|}
\hline City & $\begin{array}{c}2010 \\
\text { Production } \\
\text { subsystem } \\
\text { RRCC } \\
\text { grade }\end{array}$ & $\begin{array}{c}2010 \\
\text { Life } \\
\text { subsystem } \\
\text { RRCC } \\
\text { grade }\end{array}$ & $\begin{array}{c}2010 \\
\text { Ecological } \\
\text { subsystem } \\
\text { RRCC } \\
\text { grade }\end{array}$ & $\begin{array}{c}2015 \\
\text { Production } \\
\text { subsystem } \\
\text { RRCC } \\
\text { grade }\end{array}$ & $\begin{array}{c}2015 \\
\text { Life } \\
\text { subsystem } \\
\text { RRCC } \\
\text { grade }\end{array}$ & $\begin{array}{c}2015 \\
\text { Ecological } \\
\text { subsystem } \\
\text { RRCC } \\
\text { grade }\end{array}$ & $\begin{array}{c}2019 \\
\text { Production } \\
\text { subsystem } \\
\text { RRCC } \\
\text { grade }\end{array}$ & $\begin{array}{c}2019 \\
\text { Life } \\
\text { subsystem } \\
\text { RRCC } \\
\text { grade }\end{array}$ & $\begin{array}{c}2019 \\
\text { Ecological } \\
\text { subsystem } \\
\text { RRCC } \\
\text { grade }\end{array}$ \\
\hline Huainan & Low load & Low load & $\begin{array}{c}\text { Relatively } \\
\text { low load }\end{array}$ & $\begin{array}{l}\text { Relatively } \\
\text { low load }\end{array}$ & $\begin{array}{c}\text { Relatively } \\
\text { low load }\end{array}$ & $\begin{array}{l}\text { Relatively } \\
\text { low load }\end{array}$ & Low load & $\begin{array}{l}\text { Relatively } \\
\text { low load }\end{array}$ & Low load \\
\hline Suzhou & Low load & $\begin{array}{l}\text { Medium } \\
\text { load }\end{array}$ & Low load & $\begin{array}{l}\text { Relatively } \\
\text { low load }\end{array}$ & $\begin{array}{l}\text { Medium } \\
\text { load }\end{array}$ & $\begin{array}{l}\text { Relatively } \\
\text { low load }\end{array}$ & $\begin{array}{l}\text { Relatively } \\
\text { low load }\end{array}$ & Medium load & Low load \\
\hline Huaibei & $\begin{array}{c}\text { Relatively } \\
\text { low load }\end{array}$ & $\begin{array}{c}\text { Relatively } \\
\text { strong load }\end{array}$ & $\begin{array}{l}\text { Relatively } \\
\text { low load }\end{array}$ & Low load & Low load & Low load & Low load & Low load & Low load \\
\hline Bozhou & $\begin{array}{l}\text { Medium } \\
\text { load }\end{array}$ & $\begin{array}{l}\text { Strong } \\
\text { load }\end{array}$ & $\begin{array}{l}\text { Relatively } \\
\text { strong load }\end{array}$ & $\begin{array}{l}\text { Relatively } \\
\text { low load }\end{array}$ & Low load & $\begin{array}{l}\text { Relatively } \\
\text { low load }\end{array}$ & Low load & Low load & $\begin{array}{l}\text { Relatively } \\
\text { strong load }\end{array}$ \\
\hline Fuyang & Strong load & $\begin{array}{l}\text { Strong } \\
\text { load }\end{array}$ & $\begin{array}{l}\text { Relatively } \\
\text { strong load }\end{array}$ & $\begin{array}{l}\text { Relatively } \\
\text { strong load }\end{array}$ & $\begin{array}{l}\text { Strong } \\
\text { load }\end{array}$ & $\begin{array}{l}\text { Relatively } \\
\text { strong load }\end{array}$ & Strong load & Strong load & $\begin{array}{l}\text { Relatively } \\
\text { low load }\end{array}$ \\
\hline
\end{tabular}

mature resource-based city, while Huaibei belongs to the declining resource-based city. Except for scientific and technological resources and forestry resources, the $\mathrm{RCC}$ of various resources in Huainan were better than that in Huaibei.

\section{Resistance Diagnosis of RRCC in Coal Cities}

According to Formula (5), the resistance values of the RRCC of coal cities from 2010 to 2019 were calculated, and the resistance values of each evaluation index and each subsystem were obtained (Table 7 and Fig. 5).

Table 7 showed the top three resistance factors of coal cities in 2010, 2015 and 2019 according to their resistance values, and Fig. 5 showed the resistance values of coal cities' subsystems, showing significant differences in the change trends of the three subsystems.
As can be seen from Table 7, the resistance factors restricting the RRCC in 2010 were mainly concentrated in the ecological subsystem, with ecological compensation resources as the first resistance

Table 7. The ranking of critical resistance factors in coal cities.

\begin{tabular}{|c|c|c|c|c|}
\hline Year & Index ranking & First & Second & Third \\
\hline \multirow{2}{*}{2010} & Resistance factor & $\mathrm{C}_{9}$ & $\mathrm{C}_{10}$ & $\mathrm{C}_{2}$ \\
\cline { 2 - 5 } & Resistance value $\%$ & 20.978 & 20.092 & 9.630 \\
\hline \multirow{2}{*}{2015} & Resistance factor & $\mathrm{C}_{9}$ & $\mathrm{C}_{10}$ & $\mathrm{C}_{1}$ \\
\cline { 2 - 5 } & Resistance value $\%$ & 31.011 & 25.578 & 9.263 \\
\hline \multirow{2}{*}{2019} & Resistance factor & $\mathrm{C}_{1}$ & $\mathrm{C}_{8}$ & $\mathrm{C}_{4}$ \\
\cline { 2 - 6 } & Resistance value $\%$ & 54.226 & 33.134 & 12.641 \\
\hline
\end{tabular}




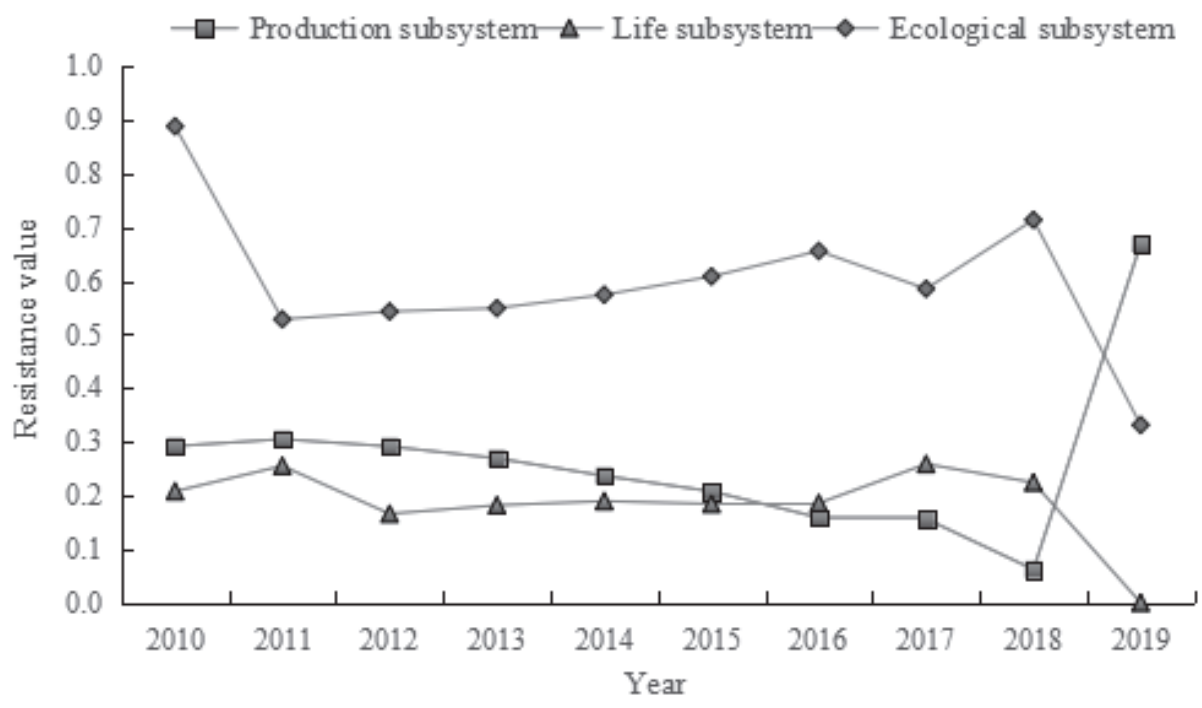

Fig. 5. The changing trend of subsystem resistance values in coal cities from 2010 to 2019.

factor and disaster prevention resources as the second resistance factor. The second was the production subsystem, whose agricultural land resources were the third resistance factor. The resistance factors in 2015 were also concentrated in the ecological subsystem. The top two resistance factors were the same as in 2010, followed by the production subsystem, whose water resource were the third resistance factor. By 2019, the resistance factors were concentrated in the production subsystem. In 2015, the third resistance factor became the first resistance factor, but industrial enterprise resources became the third resistance factor, followed by the ecological subsystem, whose forestry resources became the second resistance factor.

As can be seen from Fig. 5, although the ecological subsystem showed a fluctuating downward trend, the resistance value was in a dominant position from 2010 to 2018, which is much larger than that of the other two subsystems. The resistance value of the production subsystem was in a fluctuating downward trend from 2010 to 2018, and did not occupy a dominant position until 2019. The resistance value of the life subsystem had the least influence, which was only slightly higher than that of the production subsystem in the three years from 2016 to 2018, and was 0 until 2019.

Therefore, while promoting high-quality development, coal cities should improve the linkage mechanism of regional risk management and integrate various resistance factors of production, life and ecology for coordinated development.

\section{Discussion}

The research area is five coal cities in northern Anhui, so Anhui province is chosen as the reference area to calculate the RRCC of coal cities. From the comprehensive analysis of coal cities' RRCC in the internal and external aspects, the internal is the RCC of various resources, and the external is the RRCCC. From 2010 to 2019, the RRCCC of coal cities showed a steady upward trend, from a low load level to a relatively strong load level, and tended to a strong load level. The RCC of the internal agricultural land resources and medical resources were close to the actual total population resources, but there was still a gap. There was an obvious gap between the RCC of other resources and the actual total population resources. The RCC of disaster prevention resources was the smallest, and it was also the second critical resistance factor in 2010 and 2015. The pressure of actual population resources on disaster prevention resources should not be underestimated.

From 2010 to 2018, the ecological subsystem had the greatest resistance to RRCCC in coal cities, which had been dominant. However, by 2019, the resistance of production subsystem was greatest, followed by the ecological subsystem, and the life subsystem had no resistance. This shows that while carrying out coal exploitation, coal cities have been improving the level of geological security in the mining area and realizing the coordination between coal resources development and ecological environment protection. Because the urban economy is mainly driven by the coal industry, the intensity of industrial production is bound to increase at the same time as the capital investment to protect the ecological environment is strengthened. However, the guarantee of residents' life quality has always been the core task of sustainable development in coal cities.

There were regional differences in RRCCC level in coal cities. Fuyang as a growing resourcebased city, RRCCC was a strong load level, and the production subsystem was always at a strong load level, indicating that it was beginning to carry out large- 
scale development and utilization of resources. The life subsystem was above the relatively strong load level for a long time, indicating that the life quality of residents was more comfortable, which was suitable for the sustainable development of the city. Bozhou, Suzhou and Huainan are all mature resource-based cities. RRCCC of Bozhou and Suzhou were relatively low load level, while RRCCC of Huainan was close to relatively low load level. This indicates that the exploitation of resources has been carried out for a certain period of time. At this time, it is particularly important to promote green exploitation technology according to local conditions. The RRCCC of Huaibei was at a low load level and belongs to a declining resource-based city, facing the pressure of industrial transformation and upgrading.

Based on the improved RRCC evaluation model, this paper measured the RRCC of coal cities in Anhui Province. In addition to rating $\mathrm{RRCC}$, it also explored the supporting factors and resistance factors affecting urban development. This study not only fills part of the gap in the research field of RRCC, but also provides theoretical support for the sustainable and high-quality development of coal cities. However, in future studies, it should also consider how to select more appropriate evaluation indicators and reference areas.

Based on the above analysis, the current exploitation mode of coal cities in Anhui Province is not conducive to their sustainable development. Suggestions are as follows: (1) Enterprises should exploit coal resources rationally, optimize coal exploitation layout, strengthen green technology research and development, and increase investment in scientific and technological resources, so as to alleviate the pressure of coal resources consumption. (2) Coal cities should accelerate the industrial linkage, change the economic growth model, accelerate industrial transformation and upgrading, and promote the development of emerging industries, thus reducing regional differences. (3) The relevant departments should optimize the allocation of urban water and soil resources to ensure the development level of agriculture and forestry. At the same time, the government should strengthen comprehensive ecological management and urban cooperation, intensify ecological compensation and disaster prevention, and raise residents' awareness of resource protection. (4) The government should increase financial input, improve the level of education resources, implement medical security resources, attract and retain high-level talents, improve the rights and interests of social security services, and achieve the real integration of production, life and ecology.

\section{Conclusions}

To better realize the ecological safety construction and high-quality development of coal cities, based on the concept of production-life-ecology, this paper improved the RRCC model to obtain the PLE-EM-CPM model. From 2010 to 2019, this article analyzed the RCC of various resources and the RRCCC of coal cities in Anhui Province dynamically, evaluated the spatiotemporal dynamic evolution of the RRCCC of each city, and diagnosed the critical resistance factors. The evaluations of coal cities are summarized as follows:

(1) The RCC of agricultural land resources was the largest, followed by that of medical resources, and that of disaster prevention resources was the lowest. However, the RCC of various resources was less than the actual total population resources.

(2) The overall development trend of RRCCC was good, with the grade of RRCCC rising from low load level to relatively strong load level, and showing a development trend toward strong load level.

(3) The grade level of RRCCC in Fuyang was the highest, followed by Suzhou and Bozhou, and that of Huaibei was the lowest. The RRCCC of Huainan and Suzhou showed an upward trend, while that of other cities showed a downward trend.

(4) The resistance value of the ecological subsystem was dominant until 2019, when it became that of the production subsystem. The first critical resistance factors are also determined by the dominant subsystem.

\section{Acknowledgments}

This work was supported by the following programs: 1. The National Natural Science Foundation of China with the title 'Evaluation of coal miners' safety behavioral ability and its dynamic pre-warning under the interaction between individuals and environment" (NO.51574010). 2. Anhui University of science and technology 2021 Postgraduate Innovation Fund Project with the title "Multi dimensional measurement and prediction of water resources carrying capacity of mining cities" (2021CX1013). 3. The key project of Anhui University Humanities and social science research base with the title "Research on the safety 'awareness behavior gap' of employees in mining enterprises in China and its repair strategy" (SK2019A0101).

\section{Conflict of Interest}

The authors declare no conflict of interest.

\section{References}

1. CAO Z. Research on transformation and sustainable development of coal cities. Central South University: Changsha, China, 2013.

2. LIU L., ZHOU J.S. Analyzing ecological functions in coal mining cities based on RS and GIS. Pol. J. Environ. Stud. 27 (3), 1165, 2018.

3. SONG Y., LIU B.R., CHEN X.H., LIU J. Atmospheric pollution mapping of the Yangtze River basin: 
An AQI-based weighted co-word analysis. Int. J. Environ. Res. Public Health. 17 (3), 817, 2020.

4. CETIN M., ONAC A K., SEVIK H., SEN B. Temporal and regional change of some air pollution parameters in Bursa. Air Qual. Atmos. Health. 12 (3), 311, 2019.

5. CETIN M., SEVIK H. Change of air quality in kastamonu city in terms of particulate matter and $\mathrm{CO}_{2}$ amount. Oxid. Commun. 39 (4), 3394, 2016.

6. OZEL H.U., OZEL H.B., CETIN M., SEVIK H., GEMICI B.T., VAROL T. Base alteration of some heavy metal concentrations on local and seasonal in Bartin River. Environ. Monit. Assess. 191 (9), 2019.

7. CHI M.B., ZHANG D.S., LIU H.L., WANG H.Z., ZHOU Y.Z., ZHANG S., YU W., LIANG S.S., ZHAO Q. Simulation analysis of water resource damage feature and development degree of mining-induced fracture at ecologically fragile mining area. Environ. Earth Sci. 78 (3), 88, 2019.

8. CHANG Q., QIU Y., XIE M.M., PENG J. Theory and method of ecological risk assessment for mining areas based on the land destruction. Acta Ecologica Sinica. 32 (16), 5164, 2012.

9. WANG R.J., ZHANG J.F., SUN H., SUN S.Y., QIN G.H., SONG Y.M. Effect of different vegetation on copper accumulation of copper-mine abandoned land in tongling, China. J. Environ. Manage. 286 (4), 112227, 2021.

10. STRZALKOWSKI P., TOMICZEK K. Analytical and numerical method assessing the risk of sinkholes formation in mining areas. Int. J. Mining Sci. Technol. 25 (1), 85, 2015.

11. TAN B., LIU Y.L., Liu H., WANG H.Y., LI T.Z.Research on size effect of gas explosion in the roadway. Tunn. Undergr. Space Technol. 112, 103921, 2021.

12. CHAPMAN E.J., BYRON C.J. The flexible application of carrying capacity in ecology. Glob. Ecol. Conserv. 13, e00365, 2018.

13. CROPP R., NORBURY J. Carrying capacity - A capricious construct. Ecol. Model. 401, 20, 2019.

14. MALTHUS T.R. An essay on the principle of population 1798. University of Michigan Press: Michigan, USA, 1968.

15. VERHULST P.F. Notice sur la loi que la population suit dans son accroissement. Correspondance Mathématique et Physique. 10, 113, 1838.

16. PARK R.E., BURGESS E.W. An introduction to the science of sociology. The University of Chicago Press: Chicago, USA, 1921.

17. SEIDL I., TISDELL C.A. Carrying capacity reconsidered: From Malthus'population theory to cultural carrying capacity. Ecological Economics. 31 (3), 395, 1999.

18. UNESCO\&FAO Carrying Capacity Assessment with a pilot study of Kenya: A resource accounting methodology for exploring national options for sustainable development. food and agriculture organization of the United Nations: Rome, Italy, 1985.

19. BISHOP A B. Carrying capacity in eegional environment management. Government Printing Office: Washington, USA, 1974

20. VOGT W.(W). ZHANG Z.M.(T). Road to survival.The Commercial Press: Beijing, China, 1981.

21. GAO J.X. Theoretical Exploration of sustainable development-theory, method and application of ecological carrying capacity.China Environmental Science Press: Beijing, China, 2001.

22. KILICOGLU C., CETIN M., ARICAK B., SEVIK H. Site selection by using the multi-criteria technique - a case study of Bafra, Turkey. Environ. Monit. Assess. 192 (9), 2020.
23. WANG Y.T., CHENG H.X., HUANG L. Water resources carrying capacity evaluation of a dense city group: A comprehensive water resources carrying capacity evaluation model of Wuhan urban agglomeration. Urban Water J. 15 (7), 615, 2018.

24. AIT-AOUDIA M.N., BEREZOWSKA-AZZAG E. Water resources carrying capacity assessment: The case of Algeria's capital city. Habitat International. 58, 51, 2016.

25. GUO S.L., LI C.J., LIU S.Q., ZHOU K. Land carrying capacity in rural settlements of three gorges reservoir based on the system dynamic model. Nat. Resour. Model. 31 (2), e12152, 2018.

26. TOKARCHUK O., GABRIELE R., MAUREE O. Estimating tourism social carrying capacity. Annals of Tourism Research. 86, 102971, 2021.

27. GONSON C., PELLETIER D., ALBAN F. Social carrying capacity assessment from questionnaire and counts survey: Insights for recreational settings management in coastal areas. Marine Policy. 98, 146, 2018.

28. WANG Y.Y., PENG B.H., WEI G., ELAHI E. Comprehensive Evaluation and Spatial Difference Analysis of Regional Ecological Carrying Capacity: A Case Study of the Yangtze River Urban Agglomeration. Int. J. Environ. Res. Public Health. 16 (18), 3499, 2019.

29. WANG S., HU Z.H. Effect of regional ecological carrying capacity on economic transformation. Journal of Central South University. 24 (6), 1522, 2017.

30. IRANKHAHI M., JOZI S.A., FARSHCHI P., SHARIAT S., LIAGHATI H.Combination of GISFM and TOPSIS to evaluation of Urban Environment Carrying Capacity (Case study: Shemiran City, Iran). Int. J. Environ. Sci. Technol. 14 (6), 1317, 2017.

31. BU J.H., LI C.H., WANG X., ZHANG Y., YANG Z.W. Assessment and prediction of the water ecological carrying capacity in Changzhou city, China. Journal of Cleaner Production. 277 (7), 123988, 2020.

32. TANG M.F., WU D., FU X., CAO H,M. An assessment of ecological carrying capacity of Xilingol, Inner Mongolia. The International Journal of Sustainable Development and World Ecology. 24 (5), 408, 2017.

33. WANG Z.F., WANG Y.J., WANG L., ZHANG T.S., TANG Z.Y. Research on the comprehensive evaluation system of eco-geological environmental carrying capacity based on the analytic hierarchy process. Cluster Computing-the Journal of Networks Software Tools and Applications. 22, 5347, 2019.

34. HUANG N.S., KUANG Y.Q. The carrying capacity of resources and the problems of sustainble development in Guangdong Province.Economic Geography. (02), 52, 2000.

35. YANG J.B., DING H. A quantitative assessment of sustainable development based on relative resource carrying capacity in Jiangsu Province of China. Int. J. Environ. Res. Public Health. 15 (12), 2786, 2018.

36. BAO K.Y., HE G., JIN L., YANG J.W., ZHOU Q.T.Study on Sustainable Development of Mining Cities by the Method of Relative Resources Carrying Capacity and GM (1, 1) Model. Pol. J. Environ. Stud. 29 (6), 3983, 2020.

37. ZENG H.C., YANG Q.Y., LI W.J., XIE Y.Q. Spatialtemporal change analysis of relative carrying capacity of water resources in Hunan Province. Journal of Water Resources and Water Engineering. 29 (03), 69, 2018.

38. SU X.B., LI X.G., ZHAO J.F. Carrying capacity of water resources system coupling water resources with water environment thresholds.Resources Science. 40 (05), 1016, 2018. 
39. PENG T., DENG H.W. Comprehensive evaluation for sustainable development based on relative resource carrying capacity - a case study of Guiyang, Southwest China. Environmental Science and Pollution Research, 27 (16), 20090, 2020.

40. LI J.J., MA N. A study on industry development in ethnic regions and methods of economic growth in the respective of the relative carrying capacity of industry resources. China Population, Resources and Environment. 27 (03), 123, 2017.

41. WANG M., ZHANG X.P. Coupling coordination degree of socio-economic development with resource and environment in Zhaotong City of Yunan Province as a fragile region. Journal of University of Chinese Academy of Sciences. 34 (06), 684, 2017.

42. SI R.J.M.L., MAO P. Empirical analysis of the influence of natural resources on regional economic growth: Based on the sample of key coal cities in China from 2000 to 2016. Journal of Natural Resources. 34 (12), 2491, 2019.

43. SONG M.L., XIE Q.J. Evaluation of Urban Competitiveness of the Huaihe River Eco-Economic Belt Based on Dynamic Factor Analysis.Computational Economics. 2019.

44. ZHANG N., WANG C., WANG D. Research on the path of rural revitalization: Taking four groups of Sunjiabu
Village as an example, Airport New City in Xixian New Area. Urban Development Studies. 26 (S1), 109, 2019.

45. HE G., BAO K.Y., Wang W.W., ZHU Y.N., LI S.Z., JIN L. Assessment of Ecological Vulnerability of Resource-based Cities Based on Entropy-Set Pair Analysis. Environmental Technology. 42 (12), 1874, 2019.

46. ZHANG W.W., XU X.H., CHEN X.H. Social vulnerability assessment of earthquake disaster based on the catastrophe progression method: A Sichuan Province case study. International Journal of Disaster Risk Reduction. 24, 361, 2017.

47. SONG F., YANG X.H. Assessment of water resources carrying capacity based on improved catastrophe progression method: A case study in the lower reaches of Yangtze River. South-to-North Water Transfers and Water Science \& Technology. 16 (03), 24, 2018.

48. CHEN X.H., YANG L. Obstacle diagnosis model based on the catastrophe progression method and its applications for the small and medium-sized enterprises. Systems Engineering-Theory \& Practice. 33 (6), 1479, 2013.

49. LI H.M., JIANG Z.M., DONG G.H., WANG L.Y., HUANG X., GU X., GUO Y.J. Spatiotemporal Coupling Coordination Analysis of Social Economy and Resource Environment of Central Cities in the Yellow River Basin. Discrete Dynamics in Nature and Society. 2021, 2021. 
